\begin{tabular}{|c|c|c|c|l|l|}
\hline \multirow{2}{*}{$\mathcal{L}$} & J A M & 13946 & \multirow{2}{*}{ WILEY } & Dispatch: 21.6.18 & CE: Gayathri K \\
\cline { 2 - 3 } \cline { 5 - 6 } & Journal Code & Manuscript No. & & No. of pages: 11 & PE: Alex Leo Pau \\
\hline
\end{tabular}

Journal of Applied Microbiology ISSN 1364-5072

ORIGINAL ARTICLE

\title{
Adaptation of two groups of Oenococcus oeni strains to red and white wines: the role of acidity and phenolic compounds
}

M. Breniaux1, L. Dutilh ${ }^{1}$, M. Petrel ${ }^{2}$, E. Gontier², H. Campbell-Sills ${ }^{1,3}$, M. Deleris-Bou ${ }^{3}$, S. Krieger ${ }^{3}$, 1 P.-L. Teissedre ${ }^{1}$, M. Jourdes ${ }^{1}$, C. Reguant ${ }^{4}$ and P. Lucas ${ }^{1}$

1 Unité de recherche Enologie, Univ. Bordeaux, Villenave d'Ornon Cedex, France

2 Univ. Bordeaux, Bordeaux Imaging Center, Bordeaux, France

3 LALLEMAND SAS, Blagnac, France

24 Department of Biochemistry and Biotechnology, University Rovira i Virgili, Tarragona, Catalonia, Spain

\section{Keywords}

adaptation, diversity, fermentation, lactic acid bacteria, Oenococcus, wine.

\section{Correspondence}

Patrick Lucas, Unité de recherche Enologie, Univ. Bordeaux, EA 4577, USC 1366 INRA,

3 ISVV, 33882 Villenave d'Ornon cedex, France. E-mail: patrick.lucas@u-bordeaux.fr

2017/1951: received 29 September 2017, revised 17 April 2018 and accepted 1 June 2018

doi:10.1111/jam.13946

\begin{abstract}
Aims: Oenococcus oeni is the lactic acid bacteria species which is the most adapted to wine. Recently, two groups of strains that form two genetic lineages were described in red and white Burgundy wines. The aim of this study was to analyse the phenotypes of these strains in order to determine how they have adapted specifically to either red or white wine.

Methods and Results: Four strains from each group were tested in grape must and in wines to evaluate their tolerance to $\mathrm{pH}$ and to phenolic compound content. White wine strains proved to be the most tolerant to low $\mathrm{pH}$, both in grape must and in wine, whereas they were inhibited by the presence of grape tannins in wine. Red wine strains were more sensitive to acidity, but very resistant to phenolic compounds.

Conclusions: The results suggest that $\mathrm{pH}$ and phenolic compounds drive strain selection at several stages of wine production.

Significance and Impact of the Study: Although it is well known that O. oeni is well adapted to wine, this study shows that strains of some genetic lineages within this species have evolved to adapt better than others to specific types of wines.
\end{abstract}

\section{Introduction}

Oenococcus oeni is the lactic acid bacteria (LAB) species that is the most adapted species to wine. It is barely detectable at the surface of grape berries and in grape must, but it survives in wine and develops during or after the alcoholic fermentation (AF) performed by yeasts, reaching a population level of $10^{6}-10^{8} \mathrm{CFU}$ per $\mathrm{ml}$ (Lafon-Lafourcade et al. 1983). At this stage O. oeni is usually the single LAB species detectable in wine. It performs the malolactic fermentation (MLF), which mainly consists in the decarboxylation of malic acid into lactic acid and releases carbon dioxide (Versari et al. 1999; Cappello et al. 2017). MLF is achieved in red wines and in a number of white wines in order to reduce the sourness of malic acid and to improve the aromatic complexity and the microbiological stability of wine (Davis et al. 1985).

Oenococcus oeni is the predominant species in wine and in apple cider and it was also recently reported in kombucha fermentation (Coton et al. 2017), but it is rarely detected in other environments. Multilocus sequence typing analyses have shown that the species comprises two major lineages, named groups $\mathrm{A}$ and $\mathrm{B}$, and probably at least one additional group $\mathrm{C}$ (Bilhere et al. 2009; Bridier et al. 2010). Group A is the largest and contains only strains isolated in wine, whereas group $B$ includes strains from both wine and cider. Diverse subgroups in A and B were also described. They were associated with cider, Champagne or specific regions such as 
Chile and South Africa. Genome sequence analyses and phylogenetic tree reconstructions have confirmed the different groups and subgroups previously reported and they have provided a more detailed description of them (Campbell-Sills et al. 2015; Sternes and Borneman 2016). It was suggested that group A results from the domestication of ancestral O. oeni strains during wine making and the production of different types of wines has permitted the emergence of more specialized subgroups of strains (Campbell-Sills et al. 2015). Several other studies have reported genetic groups of strains associated with specific regions (Guerrini et al. 2003; Marques et al. 2011; Franquès et al. 2017). However, isolates of the same strain or the same genetic group were often detected in different regions, suggesting that they can disseminate over long distances (Larisika et al. 2008; Gonzalez-Arenzana et al. 2015; El Khoury et al. 2017).

A recent study has uncovered numerous genetic groups of strains in five regions of France and particularly two groups containing a vast majority of strains isolated either from red or white wines produced in Burgundy (El Khoury et al. 2017). The group associated with white wines also contains strains from Champagne and from white wines produced in other regions. All the strains of the other genetic group were isolated from Burgundy red wines, except one, which was from an Aquitaine red wine. A comparative genomics analysis of these strains has revealed a close phylogenetic proximity of both groups of strains (Campbell-Sills et al. 2017). It was suggested that the two groups appeared from a common ancestor that has evolved adapting to both types of wines.

The aim of this study was to compare the phenotypic properties of these strains in order to determine why they are preferentially associated with red or white wines. The main stressors that LAB can encounter in wine are acidity, ethanol, sulphur dioxide, temperature, phenolic compounds and inhibitors produced by yeasts (Wibowo et al. 1985). Given that white wines have usually a lower $\mathrm{pH}$ than red wines and in contrast red wines contain more phenolic compounds, these two parameters could be important for strains selection. Phenolic compounds have many different chemical structures that are grouped into nonflavonoids (phenolic acids, hydroxybenzoic acids, hydroxycinnamic acids and stilbenes) and flavonoids (anthocyanins, flavonols and flavan-3-ols). Condensed tannins are polymers of flavan-3-ol unit which can be esterified with gallic acid with varying degrees of galloylation and polymerization. Their concentration in wine depends of grape variety and maturity, as well as soil, climate conditions and winemaking practices, particularly the period of maceration during which phenolic compounds present in grape skin and seeds are extracted in wine (Gil et al. 2012). Their effect on LAB may be positive or negative depending on the nature and concentration of the compounds and on the bacterial strains (Reguant et al. 2000; Figueiredo et al. 2008; Garcia-Ruiz et al. 2011). The inhibition of bacteria may result from the interaction of the compounds with the cell membrane, which alters its permeability and leads to cell leakage (Campos et al. 2009; Garcia-Ruiz et al. 2011).

Here, we report the phenotypic characteristics of strains of the red and white wine groups, focusing on their tolerance to acidity and polyphenols content in grape must and in wine. The results provide a possible explanation for their predominance in each type of wine.

\section{Materials and methods}

\section{Bacterial strains and growth conditions}

Oenococcus oeni strains used in this study were isolated from Burgundy red and white wines (El Khoury et al. 2017) and are available through the 'Centre de Ressources Biologiques Oenologiques' of Bordeaux University (CRBO): strains CRBO_14196, CRBO_14198, CRBO_14202, CRBO_14203 from white wines and CRBO_14206, CRBO_14210, CRBO_14213, CRBO_14214 from red wine.

All strains were grown in liquid grape juice medium containing $250 \mathrm{ml} \mathrm{l}^{-1}$ pasteurized red grape juice, $5 \mathrm{~g} \mathrm{l}^{-1}$ yeast extract and $1 \mathrm{ml} \mathrm{l}^{-1}$ Tween 80, adjusted to $\mathrm{pH} 4 \cdot 0$. The cultures were incubated at $25^{\circ} \mathrm{C}$ for approx. 7 days until late exponential phase. Bacterial populations were monitored by fluorescence microscopy.

\section{Survival assays in grape musts and in wines}

Trials were performed by inoculating the strains from a freshly prepared culture to $2 \times 10^{6} \mathrm{CFU}$ per $\mathrm{ml}$ in $10 \mathrm{ml}$ of a modified grape must containing $250 \mathrm{ml} \mathrm{l}^{-1}$ grape juice (white grape variety containing $160 \mathrm{~g} \mathrm{l}^{-1}$ of sugars), $5 \mathrm{~g} \mathrm{l}^{-1}$ yeast extract, $1 \mathrm{ml} \mathrm{l}^{-1}$ Tween 80 and $6 \%$ ethanol $(\mathrm{v} / \mathrm{v})$. In the first trial, the medium was adjusted to $\mathrm{pH}$ $2 \cdot 8,3.0,3.3,3.6$ or 4.0 and in the other one, the medium was supplemented or not with $1,2.5$ or $5 \mathrm{~g} \mathrm{l}^{-1}$ of commercial preparations of tannins designated $\mathrm{T} 1, \mathrm{~T} 2$, or $\mathrm{T} 3$ (Table 1) with $\mathrm{pH}$ set at $4 \cdot 0$. Similar trials were performed in wines \#1 and \#2 (Table 2). The wines were stabilized with $200 \mathrm{mg} \mathrm{l}^{-1}$ of the preservative dimethyl dicarbonate as described in Costa et al. (2008). Controls have confirmed the absence of yeasts and bacteria in the treated wines. In a first trial the wines were adjusted to $\mathrm{pH} 2 \cdot 8,3 \cdot 0,3 \cdot 3,3 \cdot 6$ or 4.0 and in a second one they were supplemented with $1,2.5$ or $5 \mathrm{~g} \mathrm{l}^{-1}$ of the commercial product $\mathrm{T} 3$ and adjusted to $\mathrm{pH} 3.6$ with potassium 
Table 1 Composition of commercial tannins products

\begin{tabular}{|c|c|c|c|}
\hline & $\begin{array}{l}\text { T1 } \\
\text { 'Anthocyanins fraction' }\end{array}$ & $\begin{array}{l}\text { T2 } \\
\text { 'Monomeric fraction' }\end{array}$ & $\begin{array}{l}\text { T3 } \\
\text { 'Oligomeric fraction' }\end{array}$ \\
\hline $\mathrm{mDP}$ & $2 \cdot 5$ & $1 \cdot 1$ & 4.5 \\
\hline $\begin{array}{l}\text { Total proanthocyanidins } \\
\left(\mathrm{mg} \mathrm{g}^{-1}\right)\end{array}$ & $822 \cdot 0 \pm 26 \cdot 8$ & $732 \cdot 2 \pm 12 \cdot 0$ & $1000 \cdot 0 \pm 64 \cdot 3$ \\
\hline \multicolumn{4}{|l|}{ Molecular tannins $\left(\mathrm{mg} \mathrm{g}^{-1}\right)$} \\
\hline$(+)$-catechin & $20 \cdot 7 \pm 0.5$ & $144 \cdot 1 \pm 2 \cdot 0$ & $7.6 \pm 0.2$ \\
\hline (-)-epicatechin & $19.0 \pm 0.6$ & $129.6 \pm 3.4$ & $12 \cdot 9 \pm 0 \cdot 3$ \\
\hline Procyanidin dimers B1 & $19 \cdot 3 \pm 1 \cdot 6$ & $2.6 \pm 0.1$ & $1.6 \pm 0.1$ \\
\hline Procyanidin dimers B2 & $14.1 \pm 0.6$ & $2.9 \pm 0.1$ & $7 \cdot 3 \pm 0 \cdot 3$ \\
\hline Procyanidin dimers B3 & $4.9 \pm 0.4$ & $4.0 \pm 0.2$ & $0.9 \pm 0.1$ \\
\hline Procyanidin dimers B4 & $5 \cdot 3 \pm 0.8$ & $2.0 \pm 0.6$ & $2 \cdot 1 \pm 0.0$ \\
\hline Total $\left(\mathrm{mg} \mathrm{g}^{-1}\right)$ & $80 \cdot 8 \pm 4 \cdot 5$ & $285.2 \pm 3.4$ & $32.4 \pm 1.0$ \\
\hline Total anthocyanins (\%) & 10 & nd & nd \\
\hline
\end{tabular}

$\mathrm{mDP}$, mean degree of polymerization; nd, not detected.
Table 2 Composition and physicochemical properties of wines

\begin{tabular}{|c|c|c|}
\hline & Wine \#1 & Wine \#2 \\
\hline Grape variety & Chardonnay & Pinot noir \\
\hline Ethanol (\% v/v) & $12 \cdot 7$ & $12 \cdot 6$ \\
\hline $\mathrm{pH}$ & $3 \cdot 58$ & 3.60 \\
\hline L-malic acid $\left(\mathrm{g} \mathrm{I}^{-1}\right)$ & 3.4 & 1.5 \\
\hline Volatile acidity $\left(\mathrm{g} \mathrm{I}^{-1}\right)$ & 0.28 & 0.30 \\
\hline $\mathrm{mDP}$ & - & 3.5 \\
\hline Total proanthocyanidins $\left(\mathrm{g} \mathrm{I}^{-1}\right)$ & $0.116 \pm 0.004$ & $1.37 \pm 0.06$ \\
\hline \multicolumn{3}{|l|}{ Molecular tannins $\left(\mathrm{mg} \mathrm{l}^{-1}\right)$} \\
\hline$(+)$-catechin & $0.04 \pm 0.01$ & $19.4 \pm 0.39$ \\
\hline (-)-epicatechin & $0.05 \pm 0.01$ & $17 \cdot 4 \pm 0.26$ \\
\hline Procyanidin dimers B1 & nd & $1.2 \pm 0.06$ \\
\hline Procyanidin dimers B2 & nd & $1.9 \pm 0.06$ \\
\hline Procyanidin dimers B3 & nd & $5.3 \pm 0.03$ \\
\hline Procyanidin dimers B4 & nd & $3.3 \pm 0.06$ \\
\hline Total $\left(\mathrm{mg} \mathrm{I}^{-1}\right)$ & $0.09 \pm 0.02$ & $48.5 \pm 1.05$ \\
\hline Total anthocyanins $\left(\mathrm{mg} \mathrm{I}^{-1}\right)$ & nd & $145 \cdot 2 \pm 8 \cdot 4$ \\
\hline
\end{tabular}

$\mathrm{mDP}$, mean degree of polymerization; nd, not detected.

hydroxide $10 \mathrm{~N}$. After 2,7 or 14 days of incubation at $25^{\circ} \mathrm{C}$, samples were collected and serial dilutions were plated on a grape juice medium containing $250 \mathrm{ml} \mathrm{l}^{-1}$ commercial grape juice, $5 \mathrm{~g} \mathrm{l}^{-1}$ yeast extract, $20 \mathrm{~g} \mathrm{l}^{-1}$ agar, $1 \mathrm{ml} \mathrm{l}^{-1}$ Tween $80,100 \mathrm{mg} \mathrm{l}^{-1}$ pimaricin and adjusted to $\mathrm{pH} 4 \cdot 8$. Colonies were counted after 710 days of incubation at $25^{\circ} \mathrm{C}$. All assays were performed in triplicates.

\section{Cells observations by transmission electron microscopy}

To visualize the effect of polyphenols, one strain of each group AW (genetic group A, white wine) and AR (genetic group A, red wine) (CRBO_14196 and
CRBO_14213) were inoculated in red and white wines and after 1 week at $20^{\circ} \mathrm{C}$ cells were recovered by centrifugation $\left(10000 \mathrm{~g}, 10 \mathrm{~min}, 4^{\circ} \mathrm{C}\right)$. Cells pellets were fixed for $3 \mathrm{~h}$ in $0 \cdot 1 \mathrm{~mol} \mathrm{l}^{-1}$ sodium cacodylate buffer ( $\left.\mathrm{pH} 7 \cdot 2\right)$ supplemented with $2 \%$ glutaraldehyde, at room temperature. They were rinsed twice in cacodylate buffer and recovered by centrifugation $(8000 \mathrm{~g}, 3 \mathrm{~min})$. Cells inclusions were done in $1 \%$ agarose and postfixed with (i) $1 \%$ osmium tetroxide containing $1.5 \%$ potassium cyanoferrate during $1 \mathrm{~h}$ at room temperature in darkness and (ii) with $3 \%$ uranyl acetate during $45 \mathrm{~min}$ at $4{ }^{\circ} \mathrm{C}$ in darkness. They were washed three times with water during $5 \mathrm{~min}$ and gradually dehydrated in ethanol (50-100\%) and embedded in Epon $^{\mathrm{TM}}{ }^{\mathrm{T}}$ Thin sections $(60 \mathrm{~nm})$ were collected on 150-mesh copper grids, before examination with a HITACHI H7650 TEM Bordeaux Imaging Center, CNRS-INSERM, Bordeaux University.

\section{Determination of phenolic compounds in commercial products and in wines}

\section{Mean degree of polymerization}

The proanthocyanidins' mean degree of polymerization was determined by phloroglucinolysis according to Drinkine et al. (2007).

\section{Total proanthocyanidins}

Total proanthocyanidins were estimated according to Ribereau-Gayon and Stonestreet (1965). This method is based on the Bate-Smith reaction, in which proanthocyanidins release anthocyanidins by heating in an acid medium. The wines were diluted to $1: 50(\mathrm{v} / \mathrm{v})$ in a $10 \%$ ethanol solution. One millilitre of sample was added to $0.5 \mathrm{ml}$ of water and $1.5 \mathrm{ml}$ of $12 \mathrm{~mol} \mathrm{l}^{-1} \mathrm{HCl}$ and the mixture was homogenized. Two tubes were prepared per 
sample: one was incubated in boiling water for $30 \mathrm{~min}$ (sample A), while the other one was maintained at room temperature (sample B). After cooling at room temperature, $0.25 \mathrm{ml}$ of $95 \%$ ethanol were added to each sample and the absorbance at $550 \mathrm{~nm}$ was determined. Total proanthocyanidins $\left(\mathrm{g} \mathrm{l}^{-1}\right)$ were calculated as $19.33 \times$ ( $\mathrm{abs}_{550} \mathrm{~nm}$ sample $\mathrm{A}-\mathrm{abs}_{550} \mathrm{~nm}$ sample B).

\section{Total anthocyanins}

Total anthocyanins were determined using the $\mathrm{SO}_{2}$ bleaching method according to Ribereau-Gayon and Stonestreet (1965).

\section{Analysis of monomeric and dimeric flavan-3-ols}

Monomeric and dimeric flavan-3-ols: catechin, epicatechin, procyanidin dimers $(\mathrm{B} 1, \mathrm{~B} 2, \mathrm{~B} 3, \mathrm{~B} 4)$ were determined using a Thermo-Finnigan Surveyor HPLC system

6 formed by UV-Vis detector (Surveyor PDA Plus), an autosampler (Surveyor autosampler Plus) and a quaternary pump (Surveyor LC pump Plus) controlled by Xcalibur data treatment system. The separation of monomeric and dimeric flavan-3-ols was performed on a reversed phase Lichrospher C18 $(250 \mathrm{~mm} \times 4 \mathrm{~mm}, 5 \mu \mathrm{m})$ follow-

7 ing a previously described method (Chira et al. 2009). Water/formic acid (solvent A) (99:1, v/v) and acetonitrile/formic acid (99:1, v/v) (solvent B) were used at a

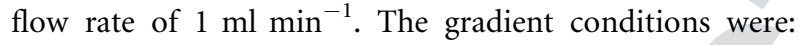
$3 \% \mathrm{~B}$ isocratic from $0-3 \mathrm{~min}, 3-5 \% \mathrm{~B}$ linear from 3$14 \mathrm{~min}, 5-10 \%$ B linear from $14-22 \mathrm{~min}, 10-14 \%$ B linear from $22-26 \mathrm{~min}, 14-25 \%$ B linear from $26-40 \mathrm{~min}$, $25-100 \%$ B linear from $40-41 \mathrm{~min}, 100 \%$ B isocratic from $41-43 \mathrm{~min}$, and $100-3 \% \mathrm{~B}$ linear from $43-44 \mathrm{~min}$, with re-equilibration of the column from 44-50 min under the initial gradient conditions. Detection was performed with a fluorescence detector set at $280 \mathrm{~nm}$ excitation wavelength and $320 \mathrm{~nm}$ emission wavelength with medium fluorescence intensity; as well as a diode array detector set at $280 \mathrm{~nm}$. Quantification was performed using an external standard calibration curves.

\section{Wine analyses}

The composition and physicochemical parameters of wines \#1 and \#2 used in this study are provided in Table 2. They were determined with methods described above and by Fourier-transform infrared spectroscopy using an OenoFOSS ${ }^{\mathrm{TM}}$ (Foss electric, Hilleroed, Denmark).

\section{Statistical analyses}

Statistical analyses were performed using the $\mathrm{R}$ software and the Kruskal-Wallis test $(\alpha=0.05)$.

\section{Results}

Tolerance to low $\mathrm{pH}$ and phenolic compounds in grape must

Four O. oeni strains from each genetic subgroup, named here AR (group A, red wine) and AW (group A, white wine) were tested in order to compare their growth capabilities in grape must and in wine. To evaluate their tolerance to $\mathrm{pH}$, they were inoculated to $2 \times 10^{6} \mathrm{CFU}$ per $\mathrm{ml}$ in a grape juice medium adjusted from $\mathrm{pH} 2 \cdot 8$ to $4 \cdot 0$. Residual bacterial populations were determined after 2 and 7 days by plate counts (Fig. 1). Two days after inoculation, all the strains of group AW survived even at the lowest $\mathrm{pH}$. After 7 days they developed under all conditions, although to a lower extent at $\mathrm{pH} 2 \cdot 8$ and $3 \cdot 0$. The strains of group AR were less resistant after the first 2 days. After 7 days, they developed well at $\mathrm{pH} 3.6$ and $4 \cdot 0$, but less at $\mathrm{pH} 3 \cdot 3$ and they were significantly inhibited at $\mathrm{pH} 3 \cdot 0$ and $2 \cdot 8$.

Their tolerance to phenolic compounds was evaluated by incubation in the presence of three commercial products containing $10 \%$ anthocyanins, $90 \%$ condensed tannins and some monomers or dimers (product T1), a majority of monomers and dimers of catechin and epicatechin (product T2), and almost exclusively condensed tannins (product T3) (Table 1). Each product was added to $1,2.5$ or $5 \mathrm{~g} \mathrm{l}^{-1}$ in a grape juice medium before inoculating bacteria. The results show that all the strains of both groups had a similar behaviour (Fig. 1c,d). After 2 days, they had almost normal growth $\left(10^{7} \mathrm{CFU}\right.$ per $\left.\mathrm{ml}\right)$ in the presence of 1 or $2.5 \mathrm{~g} \mathrm{l}^{-1}$ of each mixture. It is only with $5 \mathrm{~g} \mathrm{l}^{-1}$ which represents the highest concentration of polyphenols found in red wine-that growth was stopped, and only with products $\mathrm{T} 2$ and $\mathrm{T} 3$, since $\mathrm{T} 1$ had almost no effect. After 7 days, the impact of polyphenols was more evident, but still the same for all the strains. The inhibition of bacteria was detected only with the highest concentrations of the tested products, particularly with T3. Cell growth was stopped in the presence of $2.5 \mathrm{~g} \mathrm{l}^{-1}$ of this product and cell inactivation was the most important with $5 \mathrm{~g} \mathrm{l}^{-1}$.

\section{Effect of low $\mathrm{pH}$ in wine}

The survival of bacteria was examined after inoculation in a Chardonnay white wine and a Pinot noir red wine, both adjusted to different $\mathrm{pH}$ values (Fig. 2). In the white wine, strains of the AW group survived and developed well at $\mathrm{pH} 3 \cdot 3-4 \cdot 0$. At $\mathrm{pH} 2 \cdot 8$ and 3.0, a high mortality was observed immediately from the second day and during 2 weeks of the experiment. In the 

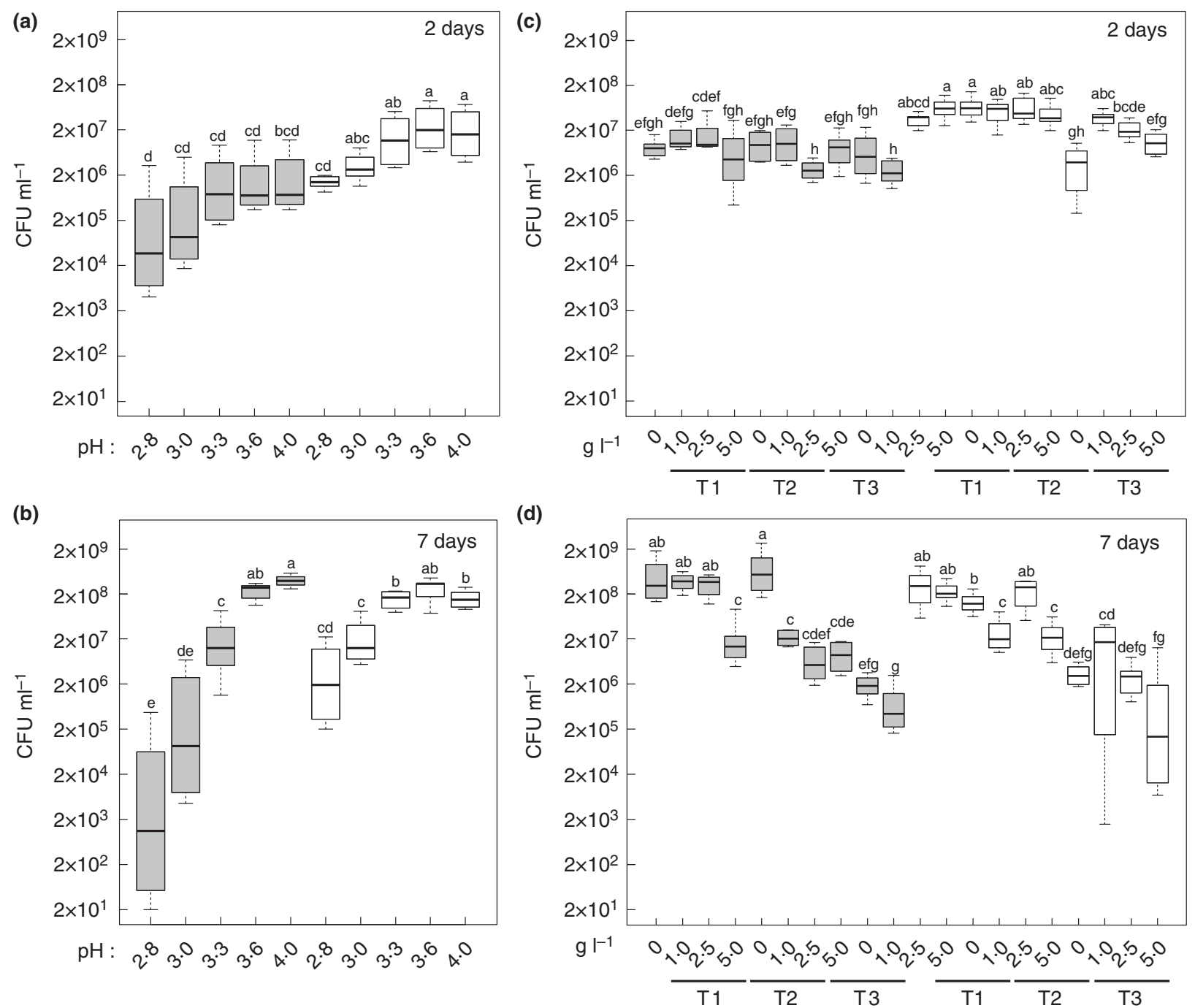

Figure 1 Survival of Oenococcus oeni strains in grape must as a function of $\mathrm{pH}$ and phenolic compounds. Four strains from genetic groups AR (grey boxes) or AW (empty boxes) were inoculated to $2 \times 10^{6} \mathrm{CFU}$ per $\mathrm{ml}$ in a commercial grape juice adjusted to various $\mathrm{pH}$ (a, b) or in the presence of $0,1,2.5$ or $5 \mathrm{~g} \mathrm{I}^{-1}$ of phenolic compound mixtures T1, T2 or T3 (c, d) and bacterial populations were monitored by plate counts after 2 days $(a, c)$ and 7 days $(b, d)$. All cultures were performed in triplicate. Boxplots represent survival population distribution for all strains belonging to one genetic group in a specific condition. Statistics differences between conditions were performed with $\mathrm{R}$ software using KruskalWallis test $(\alpha=0.05)$. Significant differences were marked with different letters.

same wine, strains of the AR group could only develop

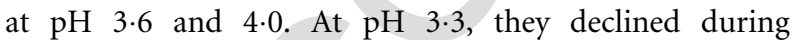
the first week and could not restart growth even after 2 weeks. Below $\mathrm{pH} 3 \cdot 3$ they have not survived at all. Figure 2 also shows the same trials performed in a red wine. The strains of both groups showed a relatively similar behaviour, being able to maintain a high population only at the highest $\mathrm{pHs}$ (3.6 and 4.0), but strains of group AW could hardly maintain a population level close to $10^{6} \mathrm{CFU}$ per $\mathrm{ml}$, whereas strains of group AR grew up to $10^{7} \mathrm{CFU}$ per $\mathrm{ml}$ and more after 2 weeks.

\section{Effect of phenolic compounds in wine}

To determine if phenolic compounds induce a stronger inhibition in wine than in grape must the tolerance of strains has been tested in red or white wines adjusted to $\mathrm{pH} 3.6$ and supplemented with product T3 that was the most inhibiting in grape must (Fig. 3). In the absence of added T3, the strains of both groups were slightly inhibited after the first 2 days, but they started growing after 1 or 2 weeks. It is interesting to note that AW group strains grew better in the white wine, while AR group strains preferred the red wine, as noticed in previous $\mathrm{pH}$ 

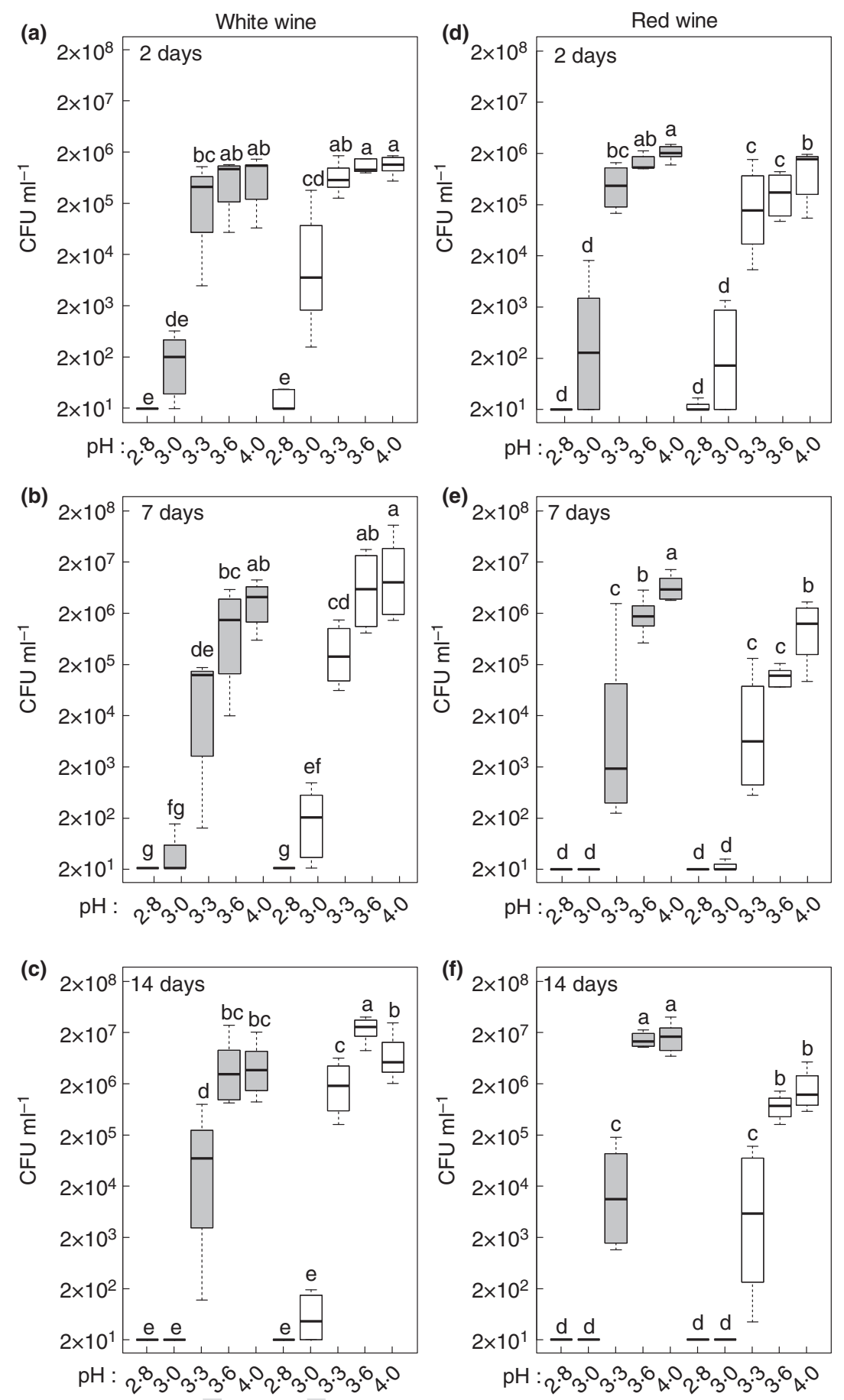

Figure 2 Influence of the $\mathrm{pH}$ on the survival of Oenococcus oeni strains inoculated in red or white wines. Four strains from genetic groups AR (grey boxes) or AW (empty boxes) were inoculated to $2 \times 10^{6} \mathrm{CFU}$ per $\mathrm{ml}$ in a white wine $(a-c)$ and a red wine $(d-f)$ adjusted to various $\mathrm{pH}$. Bacterial populations were monitored after 2 days $(a, d), 7$ days (b, e) and 14 days $(c, e)$ of incubation. Statistical analyses were performed as described in the legend of Fig. 1. trials. All the cells were significantly inhibited by addition of T3 in both types of wine, with a stronger inhibition as the concentration of the product increased. However, although AW- and AR group strains were similarly inhibited in white wine, they had a different sensitivity in red wine. Strains of the AW group were more sensitive to the addition of T3 than those of the AR group. Addition of
$1 \mathrm{~g} \mathrm{l}^{-1}$ was sufficient to reduce their population by more than 2 logs. A dose of $2.5 \mathrm{~g} \mathrm{l}^{-1}$ led to a 4 logs reduction. And $5 \mathrm{~g} \mathrm{l}^{-1}$ caused a total elimination of bacteria. In contrast, AR group strains grew well with $1 \mathrm{~g} \mathrm{l}^{-1}$ of T3. In the presence of $2.5 \mathrm{~g} \mathrm{l}^{-1}$, their population remained close to $10^{5}$ cells per ml. Only $5 \mathrm{~g} \mathrm{l}^{-1}$ of T3 could reduce their population significantly. At this concentration, they 


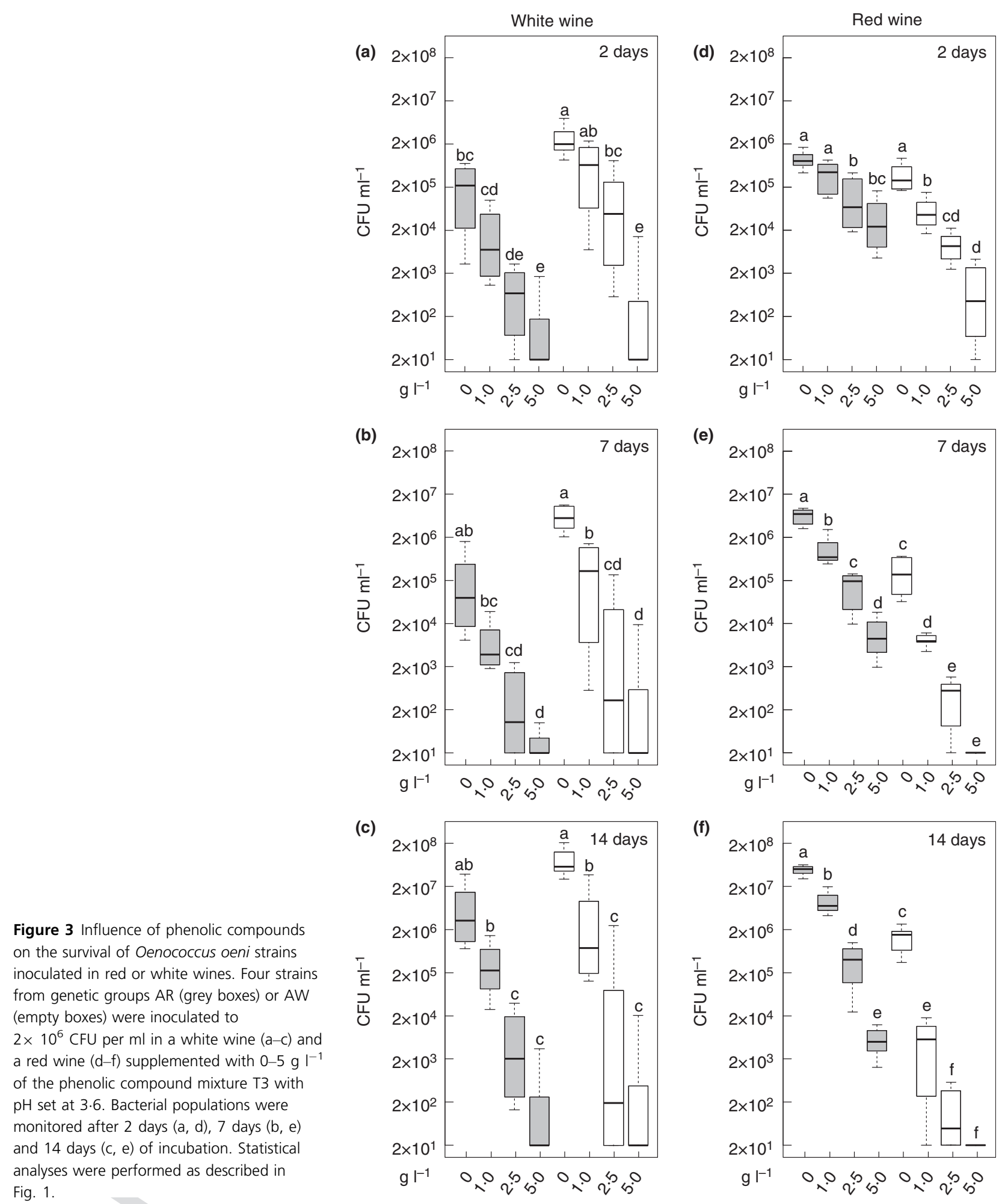

reached the same level as AW group strains incubated with only $1 \mathrm{~g} \mathrm{l}^{-1}$ of $\mathrm{T} 3$ (approx. $10^{3}-10^{4} \mathrm{CFU}$ per ml). It is noteworthy that the red and white wines used in this experiment had initial tannins concentrations of 1.37 and $0 \cdot 116 \mathrm{~g} \mathrm{l}^{-1}$, respectively, which may account in the inhibition of cells. 
Microscopy analysis of cells in wine

Electron microscopy analyses were performed to investigate whether cell morphology was modified upon exposure to wine and phenolic compounds. Figure 4 shows micrographs of strains CRBO_14196 (group AW) and CRBO_14213 (group AR) incubated for 1 week in red and white wines supplemented or not with $1 \mathrm{~g} \mathrm{l}^{-1}$ of product T3. For clarity, a single cell representative of the whole population is shown in each picture. Strain CRBO_14196 exposed to red wine had an irregular cytoplasmic organization which could be linked to its inhibition in this wine. Similar observations were reported for cells exposed to sulphites or polyphenols (García-Ruiz et al., 2010). This was not noticed when cells were incubated in the white wine, even in the presence of $1 \mathrm{~g} \mathrm{l}^{-1}$

\section{O. oeniCRBO_14196}

\section{O. oeni CRBO_14213}

White wine
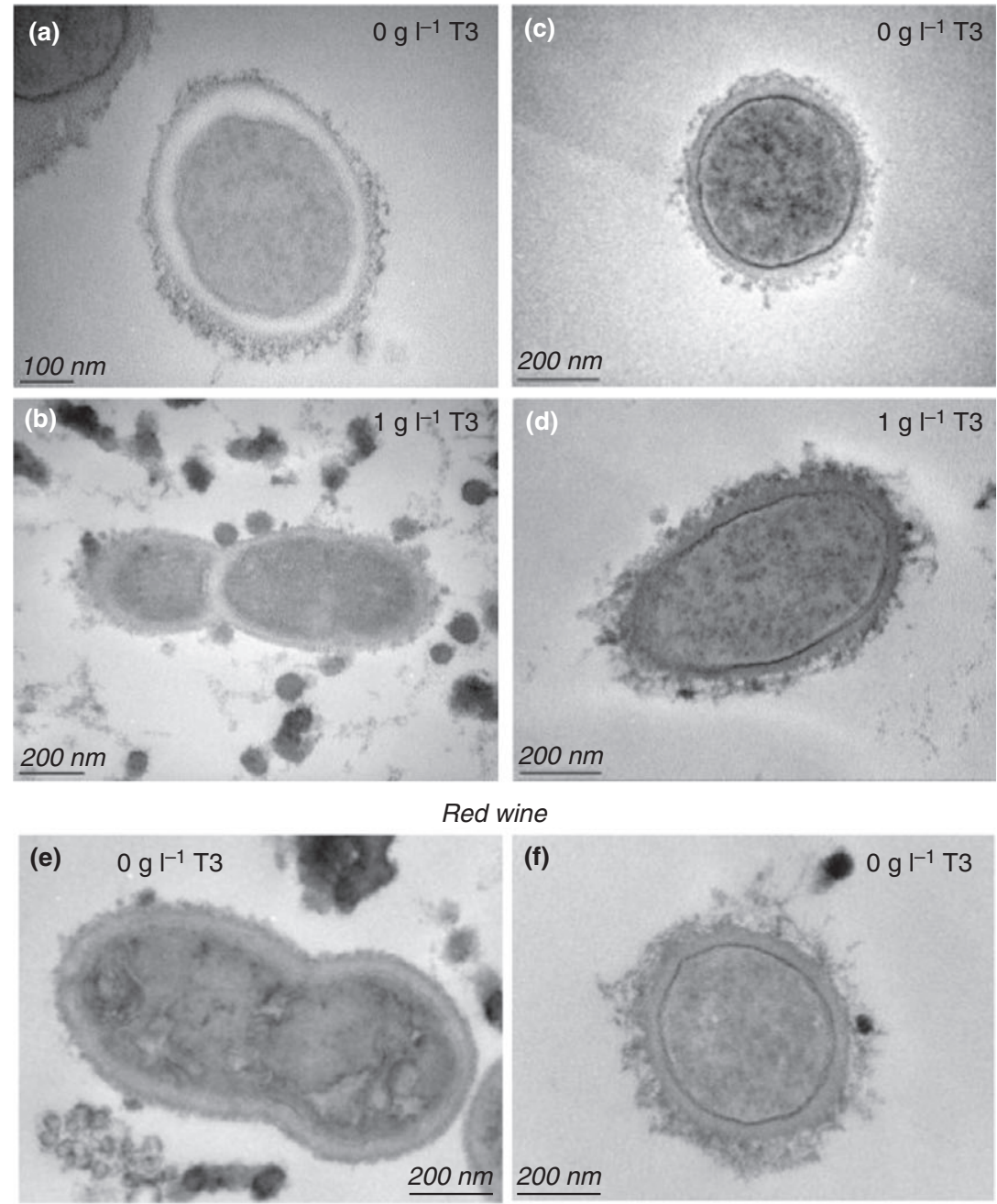

Red wine
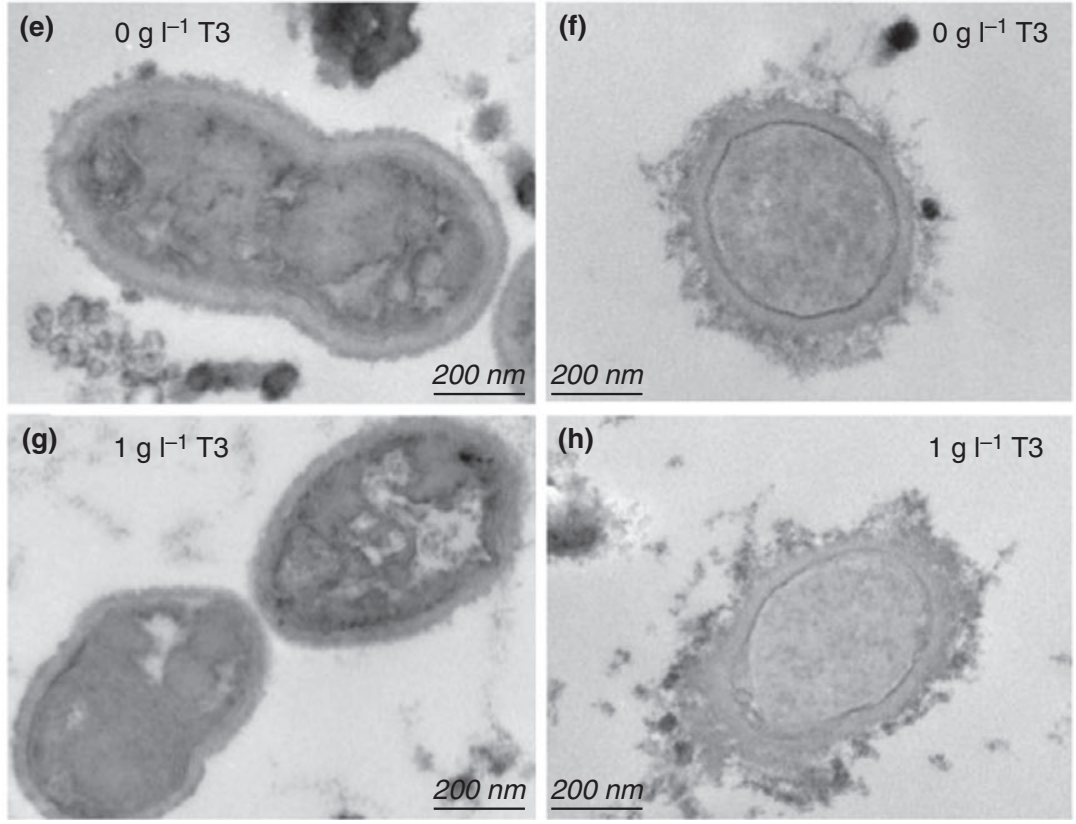

(h)

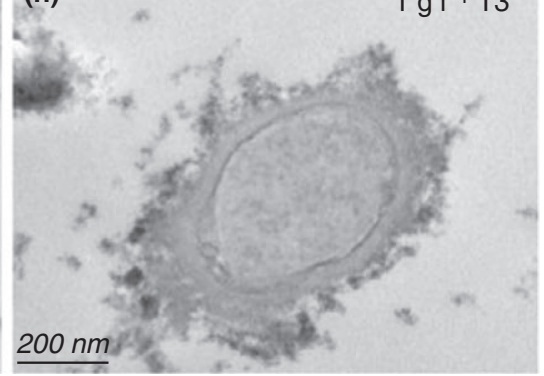

Figure 4 Electron micrographs of Oenococcus oeni CRBO_14196 and 14213 after 1 week incubation in a white and red wine supplemented or not with polyphenols. Oenococcus oeni strains CRBO_14196 (a, b, e, g) and CRBO_14213 (c, d, f, h) were incubated for 1 week in a Chardonnay and Pinot noir wine in the absence $(a, c, e, f)$ or presence $(b, d, g, h)$ of $1 \mathrm{~g} \mathrm{I}^{-1}$ of mixture T3. Each cell is representative of the sample. 
T3. In the latter conditions, cells were always surrounded by small size and dark 'pellets' which were likely composed of phenolic compounds. No cytoplasmic changes or dark pellets were detected in micrographs of the AR group strain. However, this strain appeared with a rough surface, suggesting that it was surrounded by cell-bound exopolysaccharides. The AW group strain had a smoother surface, although this does not exclude the presence of exopolysaccharides.

\section{Discussion}

This study shows that O. oeni strains of the AW- and AR groups have different phenotypes in grape must and in wines and confirms that they are specifically adapted to either red or white wine, as it was previously hypothesized (El Khoury et al. 2017). Many other strains from different genetic groups are present in these wines. However, strains of AR- and AW groups are particularly interesting because they form two well-defined genetic groups, which makes it possible to investigate their genetic characteristics (Campbell-Sills et al. 2017), and most of them were isolated from Burgundy wines, suggesting that they are present together in the vineyards and in the cellars of this region and that selection of one group or the other one occurs during the production of wines. It is well known that there is a first selection of bacteria after the harvest, when they are transferred from the surface of grape berries into the grape must. Many species do not survive the lack of oxygen, the low $\mathrm{pH}$ or other stressors in grape must (Lafon-Lafourcade et al. 1983; Piao et al. 2015). A second selection is caused by the metabolism of yeasts during AF and particularly the increase in ethanol concentration. Oenococcus oeni resists the best and usually becomes the single LAB species detectable at the end of this fermentation. However, there is a succession of $O$. oeni strains during the different steps of winemaking because strains differ in growth and stress resistance capacities (Reguant et al. 2005). Here, we found that strains of AR- and AW groups do not have the same tolerance for acidity of grape must and presence of phenolic compounds in wine, which likely contributes to selection of strains from one or the other group during red or white wine production.

Strains of the AW group proved to be the most tolerant to low $\mathrm{pH}$, particularly in grape juice, in which they developed up to $\mathrm{pH} 2 \cdot 8$, whereas AR group strains just survived up to $\mathrm{pH} 3.0$. This tolerance to low $\mathrm{pH}$ is a strong advantage for AW group strains in white wines, which are the most acidic. Champagne wines also have a low $\mathrm{pH}$, often close to or below 3.0. It is interesting to note that all the strains isolated from Champagne that have been characterized at the genomic level to date belong to this group (Bridier et al. 2010; Sternes and Borneman 2016; Campbell-Sills et al. 2017). This includes three starters commercialized by different companies. It is no coincidence that all the best adapted strains that were selected to perform MLF in Champagne are members of this group. Their high tolerance to acidity is a critical property for their use in this type of wine. All the strains of group AW contain the gtf gene, which is very rarely encountered among other O. oeni strains (Dimopoulou et al. 2016; Campbell-Sills et al. 2017). It encodes a glucosyltransferase producing a free or cell-bounded extracellular glucan which is known to improve the tolerance of bacteria to wine stressors, including low $\mathrm{pH}$ (DolsLafargue et al. 2008). However, electron micrographs analysed in this study have not shown evidences of cellbounded exopolysaccharides on the tested strain. Further experiments are required to determine whether this gene contributes significantly to the selection of AW group strains during production of white wines.

The presence of polyphenols in grape must had little effect on bacteria. Only the product T3, which is composed almost exclusively of condensed tannins, induced significant cell mortality at high concentration. This is in agreement with previous works that showed that this type of tannins can strongly affect the viability of $O$. oeni cells (Figueiredo et al. 2008). Products T1 and T2, consisting of anthocyanins and condensed tannins or catechin and epicatechin monomers and dimers, respectively, only slowed down the growth of bacteria when they were used at the highest concentration. These results are also in agreement with previous studies that showed no effect or a stimulatory effect of these compounds (Reguant et al. 2000; Alberto et al. 2001; Figueiredo et al. 2008; GarciaRuiz et al. 2009). The prevalence of AR group strains in red wines cannot be explained by the presence of polyphenols in the must as no variation was detected between the two groups of strains. In contrast, polyphenols have a selective influence in wine. Indeed, in white wine the strains of both groups were inhibited similarly, but in red wine, the strains of the AW group were strongly inhibited, while those of group AR develop well even in the presence of a very high content of T3. Electron micrographs showed that an AW group strain incubated in red wine had an irregular cytosolic organization with evident cytoplasm contractions, which may correlate with its loss of viability as noticed in previous studies (Hartmann et al. 2010; Garcia-Ruiz et al. 2011; Lyu et al. 2016). In white wine with the presence of $T 3$, cells of AW group strain were surrounded by small dark pellets, which likely represent tannins interacting with extracellular components. This was not observed for the AR group strain that in contrast appeared with a regular cytoplasm and a rough surface possibly made of cell-bounded 
exopolysaccharides. Strains of the two groups have different gene repertoires, which allow them to produce different exopolysaccharides (Campbell-Sills et al. 2017). Nevertheless, there is no evidence that these various compounds contribute to polyphenol resistance of the strains of AR group.

According to our results, bacteria of the AW group are associated with white wines because they develop well in the most acidic conditions, whereas they do not resist to polyphenols in wine. Strains of the AR group are more sensitive to acidity but they tolerate polyphenols, which favours their prevalence in red wine. These evidences that some strains lineages are genetically adapted to develop in specific types of wines, which can be important when considering the selection of industrial strains. However, this specificity does not necessarily mean that bacteria are unable to achieve MLF in another type of wine than the one from which they originate. Indeed, their phenotypic properties favour their growth during wine production and their prevalence over other strains, but if they are propagated in a culture medium and inoculated in wine, it is possible that they achieve MLF in different wines. For example, strains of group AW were unable of performing MLF when they were inoculated in a red wine, whereas those of the AR group ferment both types of wines (Campbell-Sills et al. 2017). Nevertheless, the selection of strains naturally adapted to certain types of wines could be preferred by winemakers willing to produce wines with starters that mimic the oenological quality obtained when spontaneous fermentations are performed by indigenous micro-organisms (Garofalo et al. 2015; Petruzzi et al. 2017).

\section{Acknowledgements}

This work was supported in parts by the IDEX Bordeaux (ANR-10-IDEX-03-02) and Lallemand SAS. The project was initiated in the framework of the program OENODOC of the network OENOVITI International.

\section{Conflict of Interest}

M. Bou and S. Krieger are employed by Lallemand SAS, but this does not alter the authenticity of data reported in this manuscript and their adherence with the journal policies on sharing data and materials.

\section{References}

Alberto, M.R., Farias, M.E. and Manca De Nadra, M.C. (2001) Effect of gallic acid and catechin on Lactobacillus hilgardii $5 \mathrm{w}$ growth and metabolism of organic compounds. J Agric Food Chem 49, 4359-4363.
Bilhere, E., Lucas, P.M., Claisse, O. and Lonvaud-Funel, A. (2009) Multilocus sequence typing of Oenococcus oeni: detection of two subpopulations shaped by intergenic recombination. Appl Environ Microbiol 75, 1291-1300.

Bridier, J., Claisse, O., Coton, M., Coton, E. and LonvaudFunel, A. (2010) Evidence of distinct populations and specific subpopulations within the species Oenococcus oeni. Appl Environ Microbiol 76, 7754-7764.

Campbell-Sills, H., El Khoury, M., Favier, M., Romano, A., Biasioli, F., Spano, G., Sherman, D.J., Bouchez, O. et al. (2015) Phylogenomic analysis of Oenococcus oeni reveals specific domestication of strains to cider and wines. Genome Biol Evol 7, 1506-1518.

Campbell-Sills, H., El Khoury, M., Gammacurta, M., MiotSertier, C., Dutilh, L., Vestner, J., Capozzi, V., Sherman, D. et al. (2017) Two different Oenococcus oeni lineages are associated to either red or white wines in Burgundy: genomics and metabolomics insights. OENO One 51, 309-322.

Campos, F.M., Couto, J.A., Figueiredo, A.R., Toth, I.V., Rangel, A.O. and Hogg, T.A. (2009) Cell membrane damage induced by phenolic acids on wine lactic acid bacteria. Int J Food Microbiol 135, 144-151.

Cappello, M.S., Zapparoli, G., Logrieco, A. and Bartowsky, E.J. (2017) Linking wine lactic acid bacteria diversity with wine aroma and flavour. Int J Food Microbiol 243, 16-27.

Chasseriaud, L., Krieger-Weber, S., Déléris-Bou, M., Sieczkowski, N., Jourdes, M., Teissedre, P.-L., Claisse, O. and Lonvaud-Funel, A. (2015) Hypotheses on the effects of enological tannins and total red wine phenolic compounds on Oenococcus oeni. Food Microbiol 52, 131137.

Costa, A., Barata, A., Malfeito-Ferreira, M. and Loureiro, V. (2008) Evaluation of the inhibitory effect of dimethyl dicarbonate (DMDC) against wine microorganisms. Food Microbiol 25, 422-427.

Coton, M., Pawtowski, A., Taminiau, B., Burgaud, G., Deniel, F., Coulloume-Labarthe, L., Fall, P.A., Daube, G. et al. (2017) Unravelling microbial ecology of industrial-scale kombucha fermentations by metabarcoding and culture based methods. FEMS Microbiol Ecol 93, fix048.

Davis, C.R., Wibowo, D., Eschenbruch, R., Lee, T.H. and Fleet, G.H. (1985) Practical implications of malolactic fermentation: a review. Am J Enol Vitic 36, 290-301.

Dimopoulou, M., Bardeau, T., Ramonet, P.Y., Miot-Sertier, C., Claisse, O., Doco, T., Petrel, M., Lucas, P. et al. (2016) Exopolysaccharides produced by Oenococcus oeni: from genomic and phenotypic analysis to technological valorization. Food Microbiol 53, 10-17.

Dols-Lafargue, M., Lee, H.Y., Le Marrec, C., Heyraud, A., Chambat, G. and Lonvaud-Funel, A. (2008) Characterization of gtf, a glucosyltransferase gene in the genomes of Pediococcus parvulus and Oenococcus oeni, two bacterial species commonly found in wine. Appl Environ Microbiol 74, 4079-4090. 
El Khoury, M., Campbell-Sills, H., Salin, F., Guichoux, E., Claisse, O. and Lucas, P.M. (2017) Biogeography of Oenococcus oeni reveals distinctive but nonspecific populations in wine-producing regions. Appl Environ Microbiol 83, 1-16.

Figueiredo, A.R., Campos, F., de Freitas, V., Hogg, T. and Couto, J.A. (2008) Effect of phenolic aldehydes and flavonoids on growth and inactivation of Oenococcus oeni and Lactobacillus hilgardii. Food Microbiol 25, 105-112.

Franquès, J., Araque, I., Palahí, E., del Carmen Portillo, M., Reguant, C. and Bordons, A. (2017) Presence of Oenococcus oeni and other lactic acid bacteria in grapes and wines from Priorat (Catalonia, Spain) LWT Food. Sci Technol 81, 326-334.

Garcia-Ruiz, A., Bartolome, B., Cueva, C., Martin-Alvarez, P.J. and Moreno-Arribas, M.V. (2009) Inactivation of oenological lactic acid bacteria (Lactobacillus hilgardii and Pediococcus pentosaceus) by wine phenolic compounds. J Appl Microbiol 107, 1042-1053.

Garcia-Ruiz, A., Moreno-Arribas, M.V., Martin-Alvarez, P.J. and Bartolome, B. (2011) Comparative study of the inhibitory effects of wine polyphenols on the growth of enological lactic acid bacteria. Int J Food Microbiol 145, 426-431.

Garofalo, C., El Khoury, M., Lucas, P., Bely, M., Russo, P., Spano, G. and Capozzi, V. (2015) Autochthonous starter cultures and indigenous grape variety for regional wine production. J Appl Microbiol 118, 1395-1408.

Gil, M., Kontoudakis, N., Gonzalez, E., Esteruelas, M., Fort, F., Canals, J.M. and Zamora, F. (2012) Influence of grape maturity and maceration length on color, polyphenolic composition, and polysaccharide content of cabernet sauvignon and tempranillo wines. J Agric Food Chem 60, 7988-8001.

Gonzalez-Arenzana, L., Perez-Martin, F., Palop, M.L., Sesena, S., Santamaria, P., Lopez, R. and Lopez-Alfaro, I. (2015) Genomic diversity of Oenococcus oeni populations from castilla la mancha and la rioja tempranillo red wines. Food Microbiol 49, 82-94.

Guerrini, S., Bastianini, A., Blaiotta, G., Granchi, L., Moschetti, G., Coppola, S., Romano, P. and Vincenzini, M. (2003) Phenotypic and genotypic characterization of Oenococcus oeni strains isolated from italian wines. Int $\mathrm{J}$ Food Microbiol 83, 1-14.

Hartmann, M., Berditsch, M., Hawecker, J., Ardakani, M.F., Gerthsen, D. and Ulrich, A.S. (2010) Damage of the bacterial cell envelope by antimicrobial peptides gramicidin S and PGLa as revealed by transmission and scanning electron microscopy. Antimicrob Agents Chemother 54, 3132-3142.
Lafon-Lafourcade, S., Carre, E. and Ribereau-Gayon, P. (1983) Occurrence of lactic acid bacteria during the different stages of vinification and conservation of wines. Appl Environ Microbiol 46, 874-880.

Larisika, M., Claus, H. and Konig, H. (2008) Pulsed-field gel electrophoresis for the discrimination of Oenococcus oeni isolates from different wine-growing regions in germany. Int J Food Microbiol 123, 171-176.

Lyu, Y., Yang, Y., Lyu, X., Dong, N. and Shan, A. (2016) Antimicrobial activity, improved cell selectivity and mode of action of short PMAP-36-derived peptides against bacteria and Candida. Sci Rep 6, 1-12.

Marques, A.P., Duarte, A.J., Chambel, L., Teixeira, M.F., San Romao, M.V. and Tenreiro, R. (2011) Genomic diversity of Oenococcus oeni from different winemaking regions of portugal. Int Microbiol 14, 155-162.

Petruzzi, L., Capozzi, V., Berbegal, C., Corbo, M.R., Bevilacqua, A., Spano, G. and Sinigaglia, M. (2017) Microbial resources and enological significance: opportunities and benefits. Front Microbiol 8, 1-13.

Piao, H., Hawley, E., Kopf, S., De Scenzo, R., Sealock, S., Henick-Kling, T. and Hess, M. (2015) Insights into the bacterial community and its temporal succession during the fermentation of wine grapes. Front Microbiol 6, 1-12.

Reguant, C., Bordons, A., Arola, L. and Rozes, N. (2000) Influence of phenolic compounds on the physiology of Oenococcus oeni from wine. J Appl Microbiol 88, 10651071.

Reguant, C., Carrete, R., Constanti, M. and Bordons, A. (2005) Population dynamics of Oenococcus oeni strains in a new winery and the effect of $\mathrm{SO}_{2}$ and yeast strain. FEMS Microbiol Lett 246, 111-117.

Ribereau-Gayon, P. and Stonestreet, E. (1965) Determination of anthocyanins in red wine. Bull Soc Chim Fr 9, 26492652.

Sternes, P.R. and Borneman, A.R. (2016) Consensus pangenome assembly of the specialised wine bacterium Oenococcus oeni. BMC Genom 17, 1-15.

Stivala, M.G., Villecco, M.B., Enriz, D. and Aredes Fernandez, P. (2017) Effect of phenolic compounds on viability of wine spoilage lactic acid bacteria. A structure-activity relationship study. Am J Viti Enol 68, 228-233.

Versari, A., Parpinello, G.P. and Cattaneo, M. (1999) Leuconostoc oenos and malolactic fermentation in wine: a review. J Ind Microbiol Biotechnol 23, 447-455.

Wibowo, D., Eschenbruch, R., Davis, C.R., Fleet, G.H. and Lee, T.H. (1985) Occurrence and growth of lactic acid bacteria in wine: a review. Am J Enol Vitic 36, 302-313. 